\title{
Commentary: All sheets lead to the cockpit
}

\author{
Stacey Chen, MD, and Eugene A. Grossi, MD
}

In this report, Sotolongo and colleagues ${ }^{1}$ from Yale present an additional alternative to the conundrum of the mechanics of adjusting posterior neochordal length as a component of a mitral repair. It is a variation in the long history of nonresectional repair techniques starting with McGoon's original report in $19600^{2,3}$ With a neochordal resuspension of the prolapsing segment, rather than making the primary fixation at the leaflet edge (ie, placing a knot there) with subsequent adjustments and revisions under hydrostatic testing conditions, the neochordal pair is placed in a "reversed" fashion. First, each suture needle is brought through the free leaflet edge, then the appropriate posterior papillary muscle trunk, and further into the hinge of the prolapsing segment exiting into the atrium. An annuloplasty device can then be placed, and with hydrostatic testing and a clear view, the neochordal length can be adjusted and tied easily from inside the left atrium without temporarily disrupting the coaptation zone. Just as in a sailboat, the sheets (control lines that control the angles of the sails) end in the cockpit, where they can be easily adjusted. A sailor does not adjust his sails by retying the lines on the clew.

This technique is reminiscent of the non-resectional "foldoplasty" technique advocated by Cohn, ${ }^{4}$ where the prolapsing segment is "folded under" with the prolapsing edge being sutured down with the suture ends also exiting in the base of the posterior annulus for tying in the atrium. This technique was advocated for its ability to both correct prolapse and to shorten the posterior leaflet height. It was

From the Department of Cardiothoracic Surgery, NYU Langone Health, New York, NY.

Disclosures: The authors reported no conflicts of interest.

The Journal policy requires editors and reviewers to disclose conflicts of interest and to decline handling or reviewing manuscripts for which they may have a conflict of interest. The editors and reviewers of this article have no conflicts of interest.

Received for publication Jan 21, 2020; revisions received Jan 21, 2020; accepted for publication Feb 2, 2020; available ahead of print Feb 20, 2020.

Address for reprints: Eugene A. Grossi, MD, Department of Cardiothoracic Surgery,

NYU Langone Health, 530 First Ave, Suite 9V, New York, NY 10016 (E-mail:

eugene.grossi@nyumc.org).

JTCVS Techniques 2020;2:55

2666-2507

Copyright (C) 2020 The Authors. Published by Elsevier Inc. on behalf of The American Association for Thoracic Surgery. This is an open access article under the CC BY-NCND license (http://creativecommons.org/licenses/by-nc-nd/4.0/).

https://doi.org/10.1016/j.xjtc.2020.02.007 